Third International Engineering Systems Symposium

CESUN 2012, Delft University of Technology, 18-20 June 2012

\title{
Policy and Concentration of Activities: The Case of Dutch Nanotechnology
}

\author{
Scott W. Cunningham ${ }^{1}$ and Claudia Werker $^{2}$ \\ ${ }^{1}$ Policy Analysis Section, Faculty of Technology, Policy and Management, Delft University \\ of Technology, Jaffalaan 5, Delft 2600 GA, The Netherlands \\ ${ }^{2}$ Section Economics of Innovation, Faculty of Technology, Policy and Management, Delft \\ University of Technology, Jaffalaan 5, Delft 2600 GA, The Netherlands, and RWTH Aachen \\ University, Department of Geography, Chair of Economic Geography.
}

\section{S.Cunningham@tudelft.nl, $\underline{\text { C.Werker@tudelft.nl }}$}

\begin{abstract}
Geographical concentration of economic activities has been widely discussed. However, the insights into other kinds of concentration such as technological and organizational concentration have been scarce. Here, we analyze organizational, technological and geographical concentration of nanotechnology activities in the Netherlands. We discuss our results in the light of the Dutch strategy to concentrate nanotechnology research organizationally, technologically and geographically during the last decade. Currently, this strategy is successful but will only be so if it remains open to changes in the technology itself and its environment.
\end{abstract}

Keywords. concentration, collaborations, nanotechnology, The Netherlands

\section{Introduction}

For decades nanotechnology has been infiltrating and encompassing industries, technologies and regions in the Netherlands and all over the world (Robinson et al., 2007, CEC, 2009a and b, Islam and Miyazaki, 2009, Salerno et al., 2008, as well as Meyer, 2007). Dutch nanotechnology is interesting in two respects: One, Dutch nanotechnology seems to be quite successful. Two, Dutch policy for nanotechnology is exceptional in the European context. The Dutch success can be measured when comparing investments and output. Although Dutch investment on nanotechnology was low compared to other countries the Dutch research output in nanotechnology was relatively high. Namely, the Netherlands invested $0.0089 \%$ in terms of annualised funding as a percentage of Gross National Product (GNP). This is relatively little when comparing it with Ireland which invested almost three times as much, i.e. $0.0261 \%$, or Germany which invested almost three and a half times as much, i.e. $0.0311 \%$ (Forfas, 2010). However, regarding nanotechnology publications (Miyazaki and Islam, 2007) and regarding patent applications (Hullmann, 2007) the Netherlands came fourth within the European Union (EU), following Germany, the 
U.K. and France. At the same time the Netherlands have followed a specific national nanotechnology approach. (cf. this and the following Robinson et al., 2007, Schummer, 2007, and Forfas, 2010). While this quite in line with the strategy of the U.S. and Asian countries the Dutch approach is exceptional in the European context as European countries follow a decentralized policy approach.

Worldwide we can observe concentration of economic activities. Thorough and detailed discussion on geographic concentration of economic activities have been provided (for an overview and the following see Menzel and Fornahl, 2010, as well as Werker and Athreye, 2004). While geographic concentration of economic activities is well-understood much less is known about organizational and technological concentration and its co-evolution with geographical concentration.

The goal of our paper is two-fold: One, we will shed light on the geographical, technological and organizational concentration of Dutch nanotechnology. Two, we will discuss how the concentration we find in Dutch nanotechnology is related to Dutch policy in this field. Our analysis starts with an overview of the institutional setup of Dutch nanotechnology and related policy measures and strategies (Section 2). Then, we derive indicators from the Web of Science, from Google Earth and from the NUTS system (Nomenclature of Territorial Units for Statistics) (Section 3.). Based on this we show the organizational, technological and geographical concentration of Dutch nanotechnology (Section 4.) and discuss them in the light of the specific Dutch policy approach for nanotechnology including some interesting aspects for further research (Section 5.)

\section{Nanotechnology in the Netherlands: Policy and Institutional Set- Up}

In the Netherlands, regulation on the national and increasingly the EU level has been important for nanotechnology (cf. this and the following CEC, 2009 a and b). Currently, the Commission of the European Communities (CEC) stimulates the deployment of nanotechnology within its policy framework via state aid rules, trade policy, access to finance as well as current and new initiatives in the field of so-called key enabling technologies. The Dutch government has implemented specific policy measures to stimulate and support nanotechnology; the CEC plays a less important role in this context. In the Netherlands, the government is the primary funding source of nanotechnology with more than $70 \%$ (Forfas, 2010). In particular it is the principal investor for all levels of infrastructure.

Stakeholders in the Netherlands have deliberately formed nanotechnology networks (cf. this and the following Robinson et al., 2007, Schummer, 2007, and Forfas, 2010). This approach is exceptional in the EU and much more in line with the U.S. and the Asian countries. Since the end of last century stakeholders in the U.S. and in Asia have systematically funded regional and national research organizations focusing on nanotechnology. Within the EU only the Netherlands have been following such an organized approach during the last decade. Before the beginning of this century there was almost no visible Dutch organization that focused on nanotechnology. 
The Dutch government and the three Dutch Universities of Technology as well as other stakeholders have implemented a systematic Dutch nanotechnology strategy which has evolved in time. The Netherlands federates its three leading technical universities (cf. this and the following 3TU Federation, 2010). The three universities are the Delft University of Technology, the Eindhoven University of Technology, and the University of Twente. Together the three universities are known as the "3TU." Delft is located in the west of the country, in the populous Randstad region. Eindhoven is located in the south, not far from the Belgian and German border. Eindhoven is also home to the main research campus of Philips, a major world electronics company. University of Twente is located to the east of the country, not far from the German borders. This region was home to a significant textile industry for which industrial and engineering knowledge was badly needed. The consequences of this university placement is relatively high dispersion of technological knowledge in an otherwise comparatively small country. Only the north of the country is without a technical university, although it has universities of its own.

The Dutch systematic nanotechnology strategy resulted in research groups, centres, department and laboratories in this research field which have been growing in size and output. On the national level NanoLab NL forms a consortium that builds, maintains and provides a coherent and accessible infrastructure for nanotechnology research. NanoLab NL draws on government funding and gives access to its facilities to everyone (NanoNed NL, 2010). While the basic functions provide general infrastructure suitable for common fabrication activities and can be used at most locations expert functions are normally exclusive to one location only. As a result of the Dutch national nanotechnology approach regions are technologically specialised with some substantial overlap. According to Robinson et al, 2007, the region of Groningen serves as a hub for biomolecular nanoelectronics. In the region of Twente organizations specialise in nanomaterials, complex devices and complete systems. The regions of Delft and of Eindhoven focus on micro- and nanoelectronics.

\section{Measuring Proximity and Collaboration in Dutch Nanotechnology}

For our analysis we use data from the Web of Science, Google Earth and the NUTS system (for a similar approach on European nanotechnology networks see Cunningham and Werker, forthcoming). We started by taking data from the Web of Science which include papers from the ten thousand high impact journals worldwide and 256 disciplines (Thomson Reuters, 2011). We derived our subset of nanotechnology related abstracts by using a careful query design that was developed in consultation with nanotechnology experts by Porter et al., 2008. The Porter query looks for significant nanotechnology research that is concentrated across six main Web of Science subject categories. These categories include two fields of physics (applied physics and condensed matter), two fields of chemistry (physical chemistry and multidisciplinary chemistry), materials science (multidisciplinary materials science), as well as nanoscience and nanotechnology. As a result of executing the Porter query we got more than 830,000 papers on nanotechnology published between 
1988 and 2009. The subset of the database that we will use in the following contains more than 23,900 abstracts of nanotechnology related papers, published from 2008 until 2009. For this period of time the data provide an unambiguous mapping between the list of authors, and the list of affiliations, so that we can assign authors to regions.

In the following, we investigate the one hundred most productive Dutch organizations in the field of nanotechnology, i.e. those with at least one author affiliated in the Netherlands. They account for $48 \%$ of the Dutch total number of publications. We disambiguated the names of the organizations and apportioned research to participating organizations according to total authorship (for details see Cunningham and Werker, forthcoming). We only investigate inter-organizational collaborations. This is notwithstanding the fact that internal collaboration within organizations is an important phenomenon. It goes beyond the object of this particular study though. We complemented the data of the one hundred Dutch organizations which were most productive in nanotechnology related publications, with organizational, technological and geographical information (for details see Cunningham and Werker, forthcoming).

\section{Concentration of Dutch nanotechnology}

\subsection{Geographical concentration of Dutch nanotechnology}

When looking at the results of our analysis it becomes obvious that Dutch nanotechnology its geographical, technological and organizational concentrated. Geographically, we can show that Dutch NUTS 3 regions are quite diverse regarding their nanotechnology activities. Dutch nanotechnology is concentrated in seven of the forty NUTS 3 regions in the Netherlands. These seven regions account for more than $80 \%$ of nanotechnology related publications. First comes Zuidoost-Noord-Brabant which includes Eindhoven as the largest city, second comes Delft en Westland, third Twente, then Utrecht, Groot-Amsterdam, Groningen and Leiden en Bollenstreek (see Table 1).

Table 1. Publications, citations and collaborations of leading Dutch nanotechnology Regions. Publications are fractionated as described in Cunningham and Werker, forthcoming.

\begin{tabular}{|l|l|r|r|r|}
\hline Rank & Name of Region & \multicolumn{2}{|l|}{$\begin{array}{l}\text { Number of } \\
\text { publications }\end{array}$} & \multicolumn{2}{l|}{$\begin{array}{l}\text { Average number } \\
\text { of citations }\end{array}$} & $\begin{array}{l}\text { lumber of } \\
\text { collaborations }\end{array}$ \\
\hline 1 & Zuidoost-Noord-Brabant & 1520.6 & 20.8 & 5.2 \\
\hline 2 & Delft en Westland & 1243.0 & 31.1 & 9.0 \\
\hline 3 & Twente & 1128.9 & 18.0 & 6.1 \\
\hline 4 & Utrecht & 1032.6 & 21.3 & 4.5 \\
\hline 5 & Groot-Amsterdam & 1007.2 & 24.2 & 4.7 \\
\hline 6 & Overig Groningen & 970.7 & 28.5 & 6.3 \\
\hline 7 & $\begin{array}{l}\text { Agglomeratie Leiden en } \\
\text { Bollenstreek }\end{array}$ & 672.0 & 22.5 & 4.7 \\
\hline
\end{tabular}


The region of Eindhoven (Zuidoost-Noord-Brabant) is doing particularly well concerning publications and collaborations while the region of Delft (Delft en Westland) is first regarding the average number of collaborations and average number of citations (see for this and following Table 1). While the number of publications reflects the quantity the number of citations mirrors the quality of the publication output and the number of collaborations for the actual knowledge transfer (see Section 3.). Thus, although the region of Eindhoven produces more nanotechnology related publications those produced by the region of Delft are considered more relevant by peers and therefore more often cited. Delft leading in numbers of collaborations suggests that knowledge is most often transferred via this hub.

\subsection{Technological Concentration of Dutch Nanotechnology}

Technological concentration plays a major role for the success of nanotechnology research in the Netherlands. In the following, we analyze technological specialization of Dutch provinces in nanotechnology more systematically. In particular, we answer the question whether a given region produces more or less of a particular area of knowledge than would be expected by chance. The equivalent null hypothesis, that there is no regional specialization, is equivalent to the statement that each region produces knowledge in the same proportions. Equivalently, we may say that the null hypothesis involves statistical independence between regions and the production of knowledge by subject category.

In order to find out in how far Dutch provinces are specialized regarding nanotechnology we consider the counter-factual case presented in Table 2. This table assumes that each region keeps the same publication output. It also assumes that each subject category maintains its relative significance as a fraction of nanotechnology publication. Publication output is distributed in a manner which is statistically independent across rows and across columns.

Table 2. Unspecialized regions, a counter-factual.

\begin{tabular}{|c|c|c|c|c|c|c|c|c|c|}
\hline 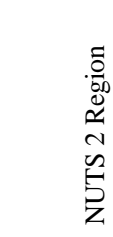 & $\begin{array}{l}\text { हूँ } \\
\text { Zू }\end{array}$ & 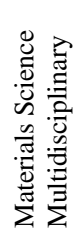 & 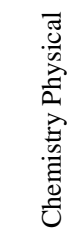 & 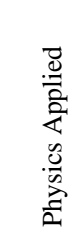 & 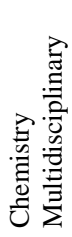 & 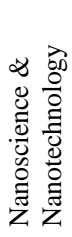 & 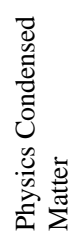 & $\begin{array}{l}\bar{\Xi} \\
\stackrel{\Xi}{0} \\
\bar{\Xi}\end{array}$ & 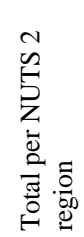 \\
\hline & & Cat1 & Cat2 & Cat3 & Cat4 & Cat5 & Cat6 & Cat7 & \\
\hline NL11 & Groningen & 39 & 35 & 23 & 31 & 25 & 20 & 159 & 333 \\
\hline NL12 & Leeuwarden & 1 & 1 & 0 & 1 & 0 & 0 & 3 & 6 \\
\hline NL21 & Enschede & 56 & 50 & 33 & 44 & 35 & 28 & 225 & 471 \\
\hline NL22 & Nijmegen & 40 & 37 & 24 & 32 & 26 & 20 & 164 & 343 \\
\hline NL31 & Utrecht & 50 & 45 & 30 & 40 & 32 & 25 & 204 & 426 \\
\hline
\end{tabular}




\begin{tabular}{|l|l|c|c|c|c|c|c|c|l|}
\hline NL32 & Amsterdam & 42 & 38 & 25 & 33 & 27 & 21 & 169 & 354 \\
\hline NL33 & Delft & 91 & 82 & 54 & 72 & 58 & 45 & 369 & 772 \\
\hline NL41 & Eindhoven & 75 & 67 & 44 & 59 & 48 & 37 & 302 & 632 \\
\hline NL42 & Maastricht & 7 & 6 & 4 & 5 & 4 & 3 & 27 & 57 \\
\hline & Total & 401 & 362 & 237 & 317 & 255 & 200 & 1622 & 3394 \\
\hline
\end{tabular}

By running the chi-squared test we are able to highlight the differences between observed publication output (Table 2) and the estimated publication output assuming statistical independence (Table 2). The test takes the squared deviation between the observed and estimated values, then divides through by the estimate:

$$
\chi 2=\frac{(O-E) 2}{E}
$$

Large departures from independence are therefore expressed as larger absolute quantities. These quantities are shown in Table 3. The more specialized regions have a higher row total; the more specialized nanotechnology topics have a higher column total. The four largest regions and subject categories in terms of specialization are noted with an asterisk. The over-all degree of specialization in the Netherlands exceeds chance with a confidence of $p<0.01$. (The resultant chi-squared test, with $\mathrm{p}=.01$ and 54 degrees of freedom results in a chi-squared value of 81.1.)

Table 3. Table of chi-squared statistics. Significant values at $\mathrm{p}<0.01$ are starred.

\begin{tabular}{|c|c|c|c|c|c|c|c|c|c|}
\hline 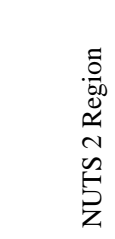 & 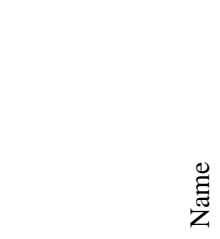 & 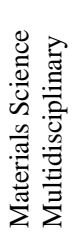 & 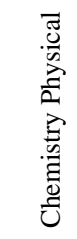 & $\begin{array}{l}\frac{0}{0} \\
: \frac{1}{2} \\
\frac{2}{2} \\
0 \\
\frac{0}{0} \\
\frac{2}{2}\end{array}$ & 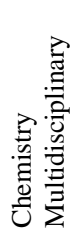 & 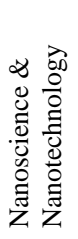 & 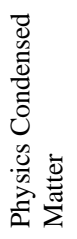 & 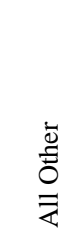 & 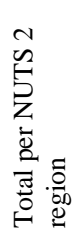 \\
\hline & & Cat1 & Cat2 & Cat3 & Cat4 & Cat5 & Cat6 & Cat7 & \\
\hline NL11 & Groningen & 0 & 1 & 0 & 1 & 1 & 1 & 1 & 4.0 \\
\hline NL12 & Leeuwarden & 1 & 0 & 0 & 1 & 0 & 0 & 3 & 6.3 \\
\hline NL21 & Enschede & 3 & 0 & 0 & 4 & 7 & 1 & 12 & $26.9 *$ \\
\hline NL22 & Nijmegen & 0 & 0 & 3 & 0 & 7 & 1 & 3 & 14.8 \\
\hline NL31 & Utrecht & 0 & 0 & 1 & 0 & 4 & 0 & 3 & 8.2 \\
\hline NL32 & Amsterdam & 11 & 0 & 5 & 5 & 6 & 1 & 25 & $53.1^{*}$ \\
\hline NL33 & Delft & 0 & 3 & 0 & 7 & 3 & 1 & 2 & $17.6^{*}$ \\
\hline NL41 & Eindhoven & 6 & 2 & 7 & 6 & 3 & 4 & 29 & $56.9 *$ \\
\hline
\end{tabular}




\begin{tabular}{|l|l|c|c|c|c|c|c|c|l|}
\hline NL42 & Maastricht & 1 & 1 & 1 & 0 & 0 & 1 & 5 & 9.9 \\
\hline & Total & $21.4^{*}$ & 8.6 & $18.9^{*}$ & 24.2 & $31.2^{*}$ & 10.1 & $83.2^{*}$ & 197.7 \\
\hline
\end{tabular}

Three of the four most specialized regions host the Dutch 3TU Federation. A fourth specialized region is Amsterdam. The four most specialized subject categories are "multidisciplinary materials science," "applied physics," "nanoscience \& nanotechnology," and the "all other" category. A comparative analysis of tables 5 and 6 is necessary to reveal whether specialization involves a comparative excess or deficit of research. Amsterdam shows a comparative excess in the "all other" category. On the other hand, it shows a deficit in production of major nanotechnology subject categories, including materials science, applied physics, and nanotechnology. In contrast, by and large the $3 \mathrm{TU}$ regions produce more materials science, applied physics, and nanotechnology than would be expected by chance. Note that this is already a nanotechnology database - so these regions are producing more specialized nanotechnology knowledge then expected given world nanotechnology profiles. And, as a consequence, these regions are producing less knowledge in the "all others" category.

\subsection{Organizational Concentration of Dutch Nanotechnology}

The organizational concentration of Dutch nanotechnology reflects the geographical and technological concentration: Of the twelve organizations that account for more than $80 \%$ of the Dutch nanotechnology publications nine are located in the seven regions that account for more than $80 \%$ of Dutch nanotechnology publications. Ten out of the twelve major players are universities, namely Delft University of Technology, the University of Twente, Eindhoven University of Technology, the University of Groningen, the University of Utrecht, Leiden University, Radboud University of Nijmegen, the University of Amsterdam, the Vrije University of Amsterdam, and the University of Wageningen. Non-universities are only Philips Research Laboratories and FOM Institute AMOLF which is one of the research laboratories of the Foundation for Fundamental Research on Matter (FOM), i.e. the physics division of the Dutch National Science Foundation (NWO).

Table 4. Central organizations in the network.

\begin{tabular}{|l|l|l|l|}
\hline $\begin{array}{l}\text { Rank } \\
\text { of all }\end{array}$ & Organization & Region & $\begin{array}{l}\text { Percent of } \\
\text { Dutch nano- } \\
\text { publications }\end{array}$ \\
\hline 1 & Delft University of Technology & 27 & 12.8 \\
\hline 2 & University of Twente & 12 & 12.0 \\
\hline 3 & Eindhoven University of Technology & 36 & 11.5 \\
\hline 4 & University of Groningen & 3 & 9.6 \\
\hline 5 & University of Utrecht & 17 & 8.7 \\
\hline 6 & Leiden University & 25 & 6.3 \\
\hline 7 & Radboud University of Nijmegen & 15 & 4.5 \\
\hline
\end{tabular}




\begin{tabular}{|l|l|l|l|}
\hline 8 & University of Amsterdam & 23 & 4.0 \\
\hline 9 & Philips Research Laboratory & 36 & 3.0 \\
\hline 10 & Vrije University of Amsterdam & 23 & 2.9 \\
\hline 11 & University of Wageningen & 13 & 2.6 \\
\hline 12 & FOM Institute AMOLF & 23 & 1.8 \\
\hline
\end{tabular}

The player with the greatest share of Dutch publications regarding nanotechnology is Eindhoven University of Technology, immediately followed by Delft University of Technology and then University of Twente (see Table 4). All three of them are major players in the national nanotechnology strategy (see Section 2). Not surprisingly the ten universities and the public sector contribute much more to the nanotechnology related publications than the private organizations (see Table 4). Philips Research Laboratories is the only privately owned research organization belonging to the twelve organizations that account for $80 \%$ of Dutch publications in the field of nanotechnology, ranking ninth with a share of $3 \%$ of Dutch total publications in this field. The list of private organizations in the Netherlands engaged in nanotechnology research contains a mix of well-known entities as well as a few surprises. Only eight organizations contribute more than a $0.1 \%$ share of Dutch publications regarding nanotechnology. The companies range from microelectronics (Philips Research Laboratories), information technology (IBM), equipment manufacturers (FEI), energy (Shell), and chemical companies (Akzo Nobel, DSM).

\section{Conclusions}

The Dutch nanotechnology network is an interesting case to analyse because it is quite successful and because the Dutch nanotechnology policy was quite different from that of other European countries in the last decade. With the help of publication data and additional organizational and geographical data we can show that Dutch nanotechnology is organizationally, technologically and geographically concentrated (Section 4). We suggest that to some extent this has emerged from the Dutch systematic national strategy to concentrate nanotechnology research in specific research organizations. This Dutch strategy of the last decade seems to work well for the Netherlands, because while Dutch nanotechnology investment has been comparatively low (Forfas, 2010) its research output in terms of patents (Hullmann, 2007) and publications has been high (Miyazaki and Islam, 2007, and section 4.1). Problems lie in the partly orchestrated dispersion of geographic activities and lack of redundancy. Insofar, the Dutch approach as a benchmark has to be considered with care regarding similar countries such as Ireland. When it comes to larger world leaders in nanotechnology such as the U.S. or Germany the Dutch approach is certainly questionable though. These countries benefit most from a broad and thorough penetration of nanotechnology research close the world-wide technological frontier.

Our analysis results in a better quantitative understanding of Dutch nanotechnology and give some hints about the role of nanotechnology policy. There are two research 
questions though that we would like to address in future work in order to enhance our understanding of the relationship between nanotechnology and policy: One, we would like to investigate which parts of the Dutch collaboration networks in nanotechnology are emerging, which parts are constructed by the systematic policy approach, and which parts are both. Two, we would like to compare the Dutch nanotechnology network and Dutch nanotechnology policy to that of other countries. Potential benchmarks would be Ireland as comparable European country and Germany as the strongest European country in nanotechnology, both with a completely different policy approach, as well as the U.S. as the world leader with a more similar policy approach (Forfas, 2010). In particular, we would like to analyse the heterogeneous structure of the network and the influence of policy and institutions in Europe by taking into consideration systemic proximity, i.e. the closeness between collaborators belonging to the same innovation system, thereby sharing the same set-up of formal and informal rules, the same policies as well as the same cultural background.

Acknowledgements. This paper is an abbreviation and an expansion of previous work presented at the Atlanta Conference on Science and Innovation Policy (Werker and Cunningham).

\section{References}

3TU (2012) About 3TU, http://www.3tu.nl/en/about_3tu/, downloaded 24.02.2012

CEC (2009a) Preparing for our future: Developing a common strategy for key enabling technologies in the EU, Communication from the Commission to the Council, the European Parliament and the European Economic and Social Committee, Brussels, 30.09.2009, $\operatorname{COM}(2009)$ 512, mimeo,

http://ec.europa.eu/enterprise/sectors/ict/files/communication_key_enabling_technologies_s ec1257_en.pdf, retrieved on 22.02.2010

CEC (Commission of the European Communities) (2009b) Nanosciences and Nanotechnologies: An Action plan for Europe 2005-2009. Second Implementation Report, 2007-2009, Communication from the Commission to the Council, the European Parliament and the European Economic and Social Committee, Brussels, 29.10.2009, COM(2009) 607, mimeo, http://ec.europa.eu/research/industrial technologies/pdf/nano action plan en.pdf, retrieved on 22.02 .2010

Cunningham S, Werker C (forthcoming) Proximity and collaboration in European nanotechnology, in: Papers of Regional Science, in press, preprint available online http://onlinelibrary.wiley.com/doi/10.1111/j.1435-5957.2012.00416.x/abstract

Forfas (2010): Ireland's Nanotechnology Commercialisation Framework 2010-2014 http://www.forfas.ie/media/forfas310810-nanotech commercialisation framework 20102014.pdf, downloaded on 10.02.11

Hullman A (2007) Measuring and Assessing the Development of Nanotechnology. Scientometrics 70: 739-758

Islam N and K Miyazaki (2009) Nanotechnology innovation system: Understanding hidden dynamics of nanoscience fusion trajectories. Technological Forecasting and Social Change 76: $128-140$ 
Maggioni MA, Nosvelli M, Uberti TE (2007) Space versus networks in the geography of innovation: A European analysis, Papers in Regional Science, 86(3): 471-493.

Meyer, M (2007) What do I know about innovation in nanotechnology? Some propositions about an emerging field between hype and path-dependency. Scientometrics 70: 779-810

Menzel MP, Fornahl D (2010) Cluster life cycles-dimensions and rationales of cluster evolution, Industrial and Corporate Change, 19 (1), 205-238.

Miyazaki K, Islam N (2007) Nanotechnology systems of innovation - An analysis of industry and academia research activities, Technovation, 27: 661-675

NanoNed NL (2010) Nanotechnology in the Netherlands, downloaded 12 juli 2010, http://www.nanoned.nl/nanolab-nl/about-nanolab-nl.html

Newman, MEJ (2001) The structure of scientific collaboration networks. Proceedings of the National Academy of Science 98: 404-409

Porter AL, Youtie J, Shapira P, Schoeneck DJ (2008), Refining Search Terms for Nanotechnology, Journal of Nanoparticle Research, 10: 715-728.

Robinson DKR, Rip A and Mangematin V (2007) Technological agglomeration and the emergence of clusters and networks in nanotechnology. Research Policy 36: 871-879

Salerno M, Landoni P and Verganti R (2008) Designing foresight studies for Nanoscience and Nanotechnology (NST) future developments. Technological Forecasting and Social Change 75: 1202-1223

Schummer J (2004) Multidisciplinarity, interdisciplinarity, and patterns of research collaboration in nanoscience and nanotechnology. Scientometrics 59: 425-465

Thomson Reuters (2011): Web of Science,

http://thomsonreuters.com/products_services/science/science_products/a-z/web_of_science/, downloaded on 27.02. 2011

Werker C, Athreye SS (2004) 'Marshall's Disciples: Knowledge and Innovation Driving Regional Economic Development and Growth. Journal of Evolutionary Economics 14: 505523

Werker, C., Cunningham, S. (2012). Policy and Concentration of Activities: The Case of Dutch Nanotechnology, In: Proceedings of the 2011 Conference on Science and Innovation Policy, 15-17 Sept., Atlanta, GA. http://ieeexplore.ieee.org/xpls/abs_all.jsp?arnumber=6064495\&tag=1 